\title{
Microsatellite Instability Incidence in Recurrent Colon Cancer Stage II and III
}

Guzmán-Casta Jordi ${ }^{1,2^{*}}$, Riera-Sala Rodrigo Fernando ${ }^{1}$, Martínez-Vega Rocío Pamela ${ }^{5}$, Rubio-Cordero Jairo Aaron ${ }^{2}$, Téllez-Campos Lucía², Baltazar-Contreras Rocío del Carmen², Carrasco-Cara Chards Sonia ${ }^{3}$, Guzmán-Huesca Jorge ${ }^{4}$, González-Araujo Andrea ${ }^{6}$, Hernández-Dehesa Itzel Ariadna7, Domínguez Ayala Adriana ${ }^{10}$, Correa-Cano Rafael ${ }^{9}$, Elvira-Fabián Karina ${ }^{8}$, Escobar-Gómez Mario², Lázaro-León Jesús Miguel² $^{2}$

${ }^{1}$ Department of Clinical Oncology, Instituto Nacional de Enfermedades Respiratorias, Ciudad de México, México.

${ }^{2}$ Department of Clinical Oncology, Hospital General de México "Dr. Eduardo Liceaga", Ciudad de México, México.

${ }^{3}$ Facultad de Medicina, Universidad Nacional Autónoma de México, Ciudad de México, México.

${ }^{4}$ Bonita Community Health Center, Internal Medicine, Bonita Springs, Florida, United States

${ }^{5}$ Nutritional Department, Hospital General de México "Dr. Eduardo Liceaga" Ciudad de México, México

${ }^{6}$ Resident of Primary Care, Instituto del Seguro Social "IMSS", Guanajuato, México

'Department of Radiology, Hospital Ángeles Acoxpa, Ciudad de México

${ }^{8}$ Centro Médico Hospital ABC Santa Fé, Ciudad de México, México.

${ }^{9}$ Resident of Clinical Oncology, Centro Médico Nacional Siglo XXI "IMSS", Ciudad de México, México.

${ }^{10}$ Department of Radiooncology, Centro Médico Naxcional 20 de Noviembre "ISSSTE", Ciudad de México, México

Correspondence to: Guzmán-Casta Jordi, Department of Clinical Oncology, Instituto Nacional de Enfermedades Respiratorias, Ciudad de México, México. Received date: November 22, 2020; Accepted date: December 6, 2020; Published date: December 13, 2020

Citation: Jordi GC, Rodrigo FernandoRS, Rocío Pamela MV, et al. (2020) Microsatellite Instability Incidence in Recurrent Colon Cancer Stage II and III. J Med Res Surg 1(6): pp. 1-5.

Copyright: @2020 Jordi GC, et al. This is an open-access article distributed under the terms of the Creative Commons Attribution License, which permits unrestricted use, distribution and reproduction in any medium, provided the original author and source are credited.

\section{ABSTRACT}

Objective: To evaluate the incidence of Microsatellite Instability (MSI) in patients with Colon Cancer in stage II \& III in the Mexican population.

Methods: This is a descriptive, retrospective and cross-sectional study performed through a review of 30 clinical charts of patients with the diagnosis of Colorectal Cancer and evaluation of Microsatellite Instability in surgical pathology specimens.

Results: Males with $53.3 \%$ had a higher incidence than females. The most frequent site was the left colon (53\%), followed by the right colon (16.6\%), higher rectum (10\%), mid rectum (10\%), and lower rectum (10\%). The majority of the patient were classified as moderately differentiated (86.7\%), with $6.7 \%$ being poorly differentiated and the rest $6.7 \%$ well differentiated. For the presence of MSI in repair genes (MLH1, MSH2, PMS2), this was positive in 33\% of the population studied. The clinical-stage most frequently affected was IIA with $36.7 \%$ of the positive cases followed by stage IIB with $20 \%$, stage IIIA $20 \%$, and finally, stage IIC and IIIB with $13 \%$ and $10 \%$ respectively. Among histologic subtypes, adenocarcinoma was found in $90 \%$ of the cases, mucinous carcinoma in $6.7 \%$, and signet ring cell carcinoma in $3.3 \%$. In regards to treatment, $50 \%$ of patients underwent only surgery while the other $50 \%$ were treated with surgery followed by adjuvant chemotherapy. Clean surgical margins were achieved in $93.7 \%$ after initial surgery and the rest were taken back to surgery for a wider resection. The predominant tumor size was T2 (50\%), T3 (33\%), and T4a $(16.7 \%)$. The most commonly found lymph node involvement was N1a with $63.3 \%$ of the cases followed by N1b with $16.7 \%$. In terms of recurrent metastatic disease, M1a was the most frequent, found in $73.3 \%$ of the cases.

Conclusion: In our study population in contrast with current literature from the rest of the world we found a higher presence of microsatellite instability ( $33 \%$ vs $15 \%$ ) and a higher incidence in the left colon with a definitive impact in the survival of patients.

\section{Keywords:}

Colon cancer recurrent, Microsatellite instability, Stage II, Stage III.

\section{Introduction}

Colorectal Cancer (CRC) is the third most common malignancy in the western world and the second most common cause of cancer death in North America. It presents as a heterogeneous disease at the molecular level. Several studies have evaluated the different molecular subtypes, histopathology classification and clinical characteristics of CRC, finding the Microsatellite Instability (MSI) as a biological factor determining prognosis and treatment. Four Consensus Molecular Subtypes (CMS) in Colorectal Cancer (CRC) were identified in a study by Justin Guinney. MSI was the main characteristic for CMS1 (Immune Hypermethylation and an important activation of the immune system) [1-3].

The most common presentation is sporadic (85\%) or associated with Lynch Syndrome (Hereditary Non-Polyposis Colon Cancer). The majority of cases occur as a consequence of sporadic methylation of hMLH1 (95\%-97\%). The MSI-H phenotype is an identity seal of CRC associated with Lynch Syndrome and it is diagnostic of it [4-6]. 
Microsatellites are small repetitive Deoxyribonucleic Acid (DNA) sequences from 1 to 6 bases distributed along the genome in both coding and non-coding regions. Microsatellite Instability (MSI) is a molecular change particularly distinctive in approximately $15 \%$ of the case of Colorectal Cancer $[7,8]$.

Since 1998, we have learned that patients with high Microsatellite Instability (MSI-H) show a different clinical behavior, less aggressive course and a more favorable prognosis compared to the rest of the patients. It was Ribic et al. who initially described how patients with MSI-H tumors had a modestly better prognosis than those with tumors showing low microsatellite instability $[9,10]$.

The molecular cause in Colorectal Cancer with $\mathrm{MSI}-\mathrm{H}$ is a deficiency in the DNA Mismatch Repair (MMR). MLH1 and $\mathrm{MSH} 2$ genes are inactivated in $90 \%$ of Colorectal tumors with MSI. In the sporadic tumors, the inactivated gene is MLH1 and in more than $80 \%$ of the cases, this inactivation is produced by methylation of the promoter $[11,12]$.

The MSI-H phenotype shows an association with a more proximal localization of the tumor, an important infiltration of lymphocytes, and a low incidence of distant metastasis. These MSI-H sporadic tumors typically develop in the proximal colon and have a female preponderance. In young patients presenting with Colorectal Cancer, the MSI-H phenotype is closely associated with Lynch Syndrome $[13,14]$.

One of the histopathologic characteristics of MSI-H colorectal cancer is a high density of lymphocyte infiltration of the tumor. They generally have a mixed differentiation encompassing subtypes like signet ring cells, mucinous and medullary carcinoma. The evidence has shown that mutations in the Beta-2-Microglobulin (B2M) are associated with an absence of distant metastasis in patients with MSI-H Colorectal Cancer [15-17].

Recent independent studies have demonstrated that patients with a mutated $\mathrm{B} 2 \mathrm{M}$ gene in $\mathrm{MSI}-\mathrm{H}$ CRC have a remission free survival significantly longer compared to patients with a nonmutated B2M MSI-H Colorectal Cancer [18].

In recent years, the hypothesis that patients with MSI-H CRC show a decreased sensitivity to 5-Fluorouracil chemotherapy has been supported by various studies, including in vitro studies, experimental studies in mice and other clinical assays. MSH-1 Colorectal Cancer has a better prognosis than CRC with microsatellite stability. It's been suggested that such prognosis has to do with malignancies associated with Lynch Syndrome and therefore a higher antitumor immune response $[19,20]$.

The hypothetical predictive role of MSI with the response to 5-Fluorouracil based adjuvant chemotherapy has proven to be a rather more difficult topic to sort out. Adjuvant chemotherapy in patients with Stage II CRC is still a controversial topic. In a 2011 article by Sinicrope et al. about 2141 patients with CRC they found a benefit with 5-Fluorouracil in patients with MSI in Stage II cancers compared to other studies reported in the literature [5,21,22].

In Clinical Stage II tumors are highly heterogeneous with 5 -year overall survival rates ranging from $58.4 \%$ to $87.5 \%$. The European Society of Medical Oncology recommends that MSI should be evaluated in Stage II CRC to help with treatment and make decisions with regards to the administration of adjuvant chemotherapy [23-24].

\section{Results}

Figures 1-11 showing the results of the study.

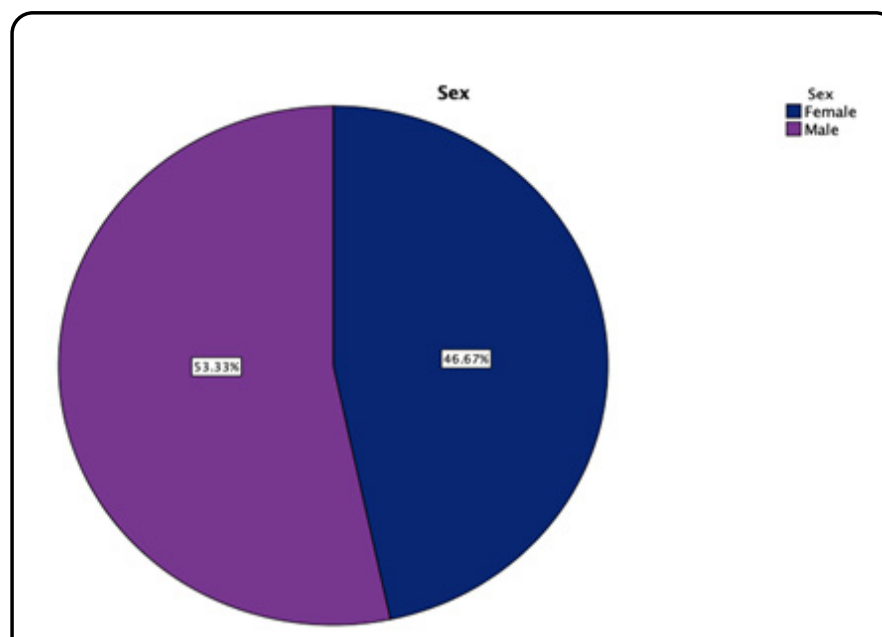

Figure 1: The incidence was minimally higher in men by $53.33 \%$ versus $46.67 \%$ in women.

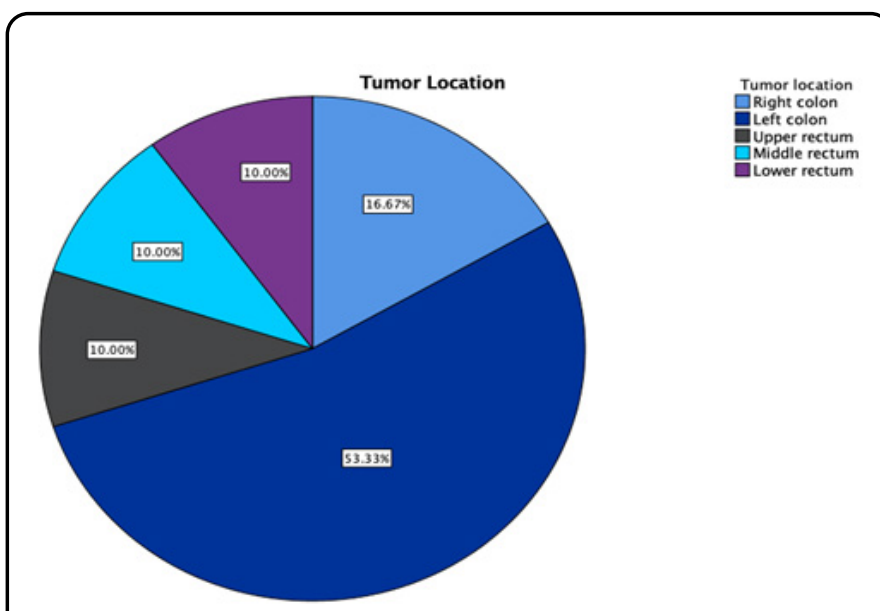

Figure 2: More than half of the patients evaluated had a tumor location in the left colon $53.33 \%$.

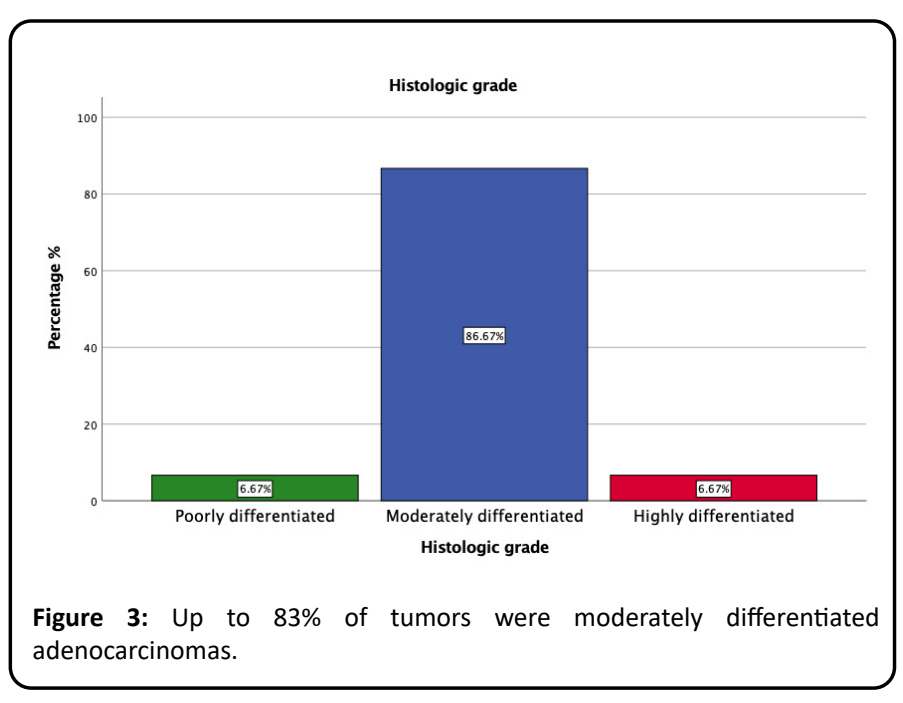




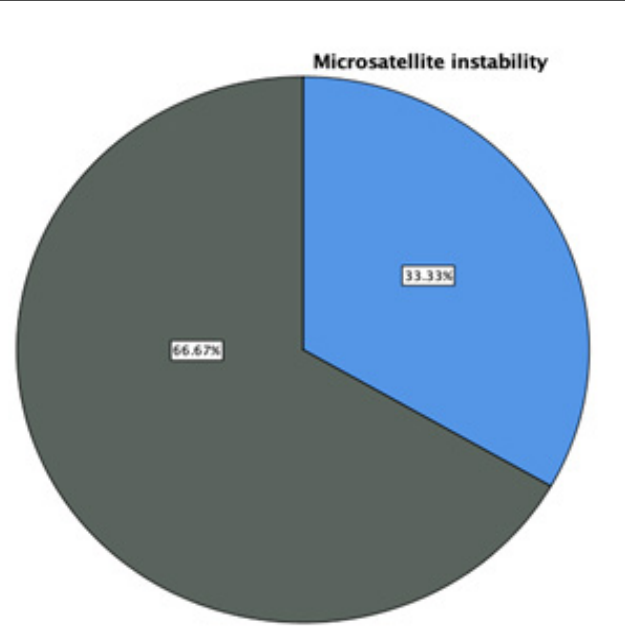

Figure 4: The incidence of microsatellite instability was $66.7 \%$ in recurrent tumors.

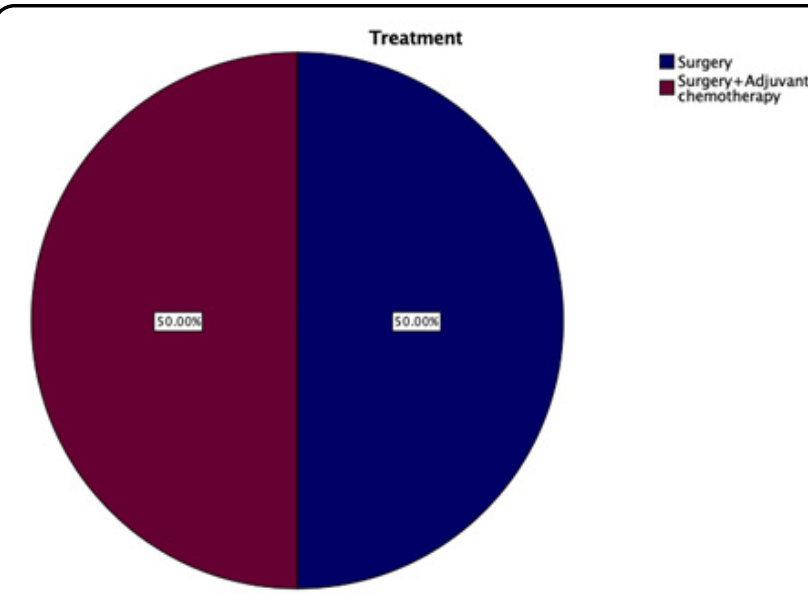

Figure 5: Half of the patients were only taken to surgery and the other half was added adjuvant chemotherapy.

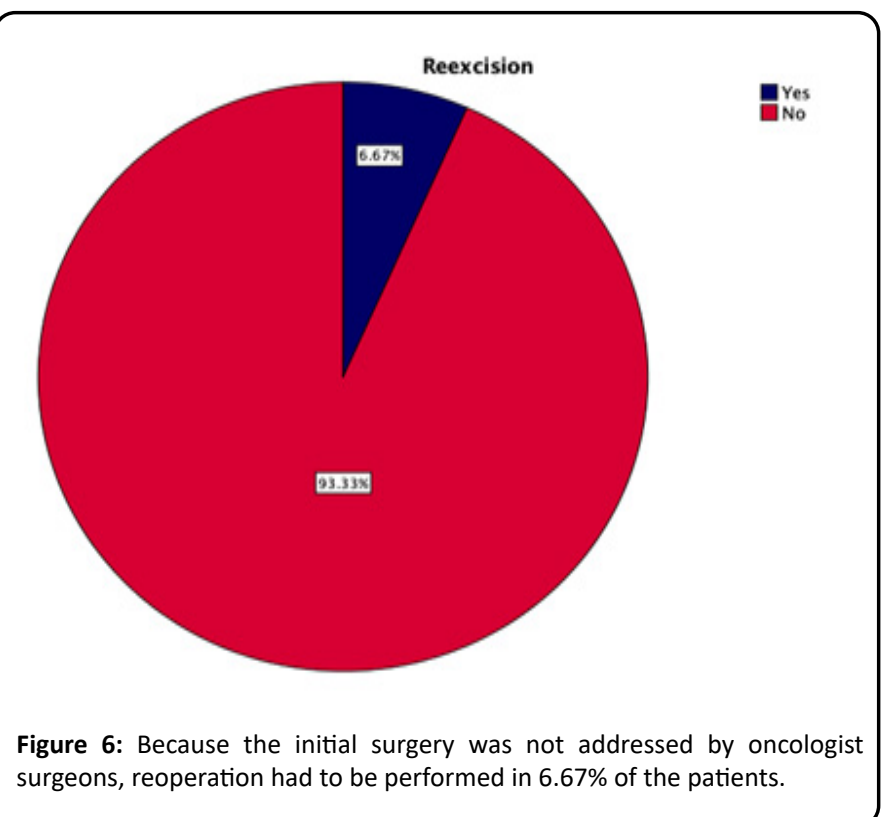

J Med Res Surg, OPEN 2 ACCESS
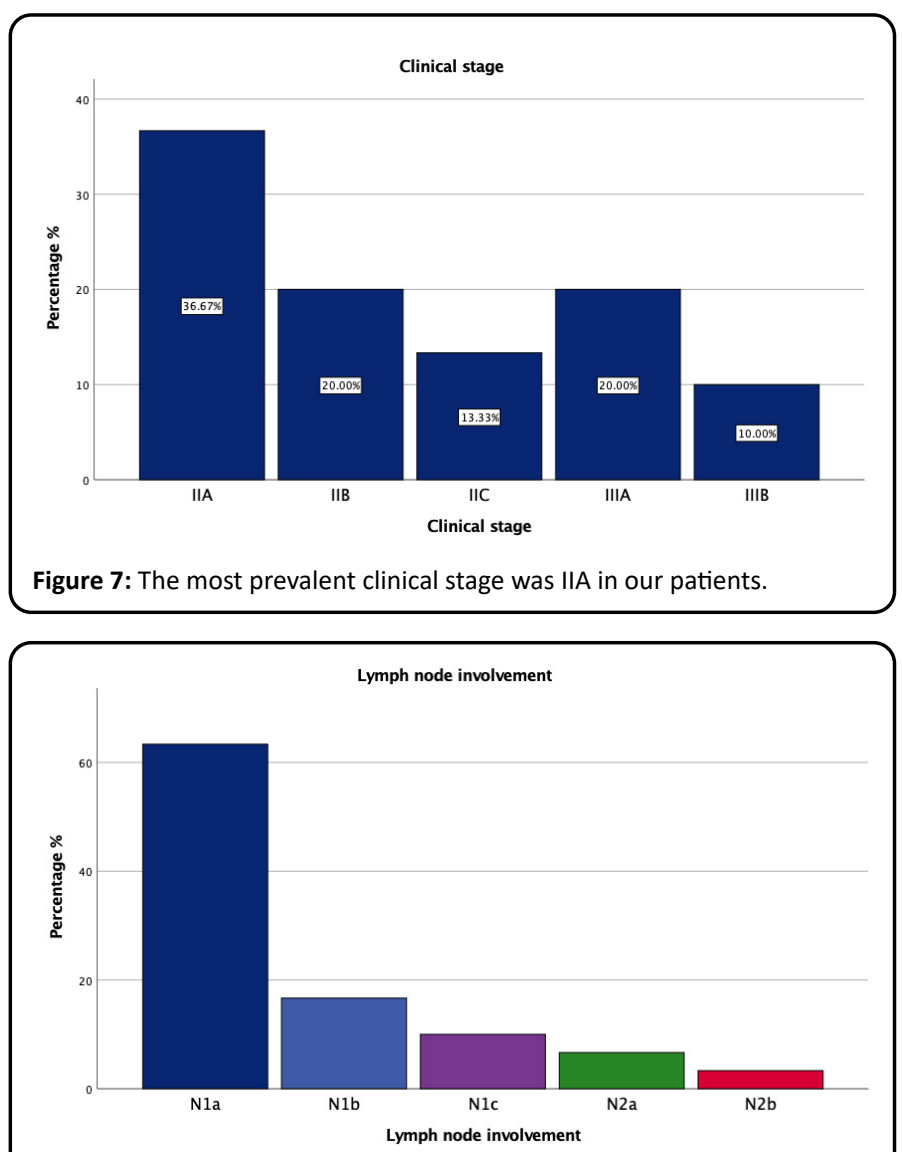

Figure 8: The incidence of lymph node involvement was greater than $60 \%$ in the postsurgical evaluation.

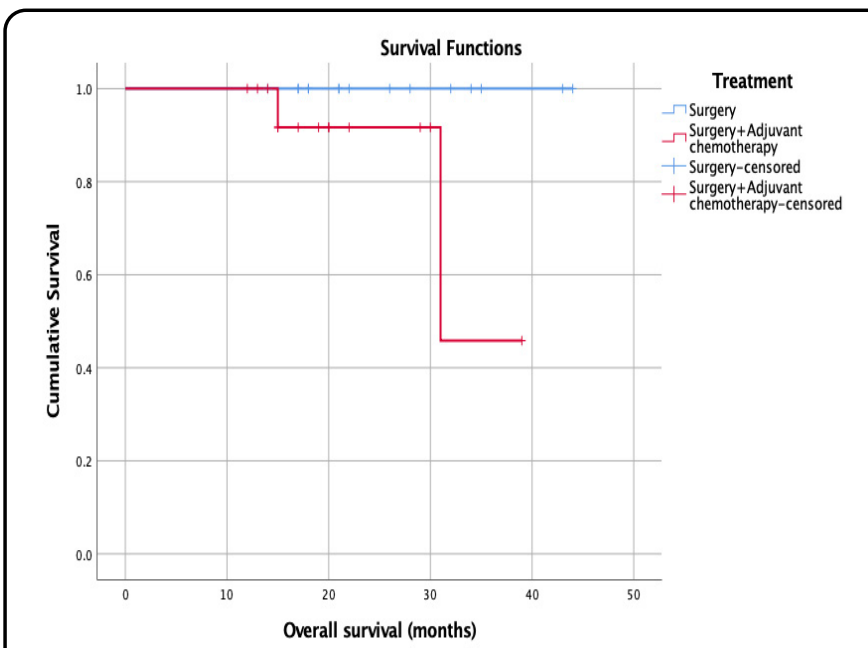

Figure 9: We observed that in the global survival follo w-up to more than 40 months, $100 \%$ of the patients who only underwent surgery were still alive.

\section{Discussion}

Our population studied was from a single institution (General Hospital of México City), with a total of 30 patients included, the results of the presence of Microsatellite Instability (MSI) were significantly higher than those reported in other international studies where the usual incidence oscillates between $10 \%$ and $15 \%$ at the maximum and has more prevalence in the right colon, however in our population the incidence reached up to $33.3 \%$ for the presence of MSI with a higher incidence of the left colon which is in contrast with previous reports. For tumor size, 


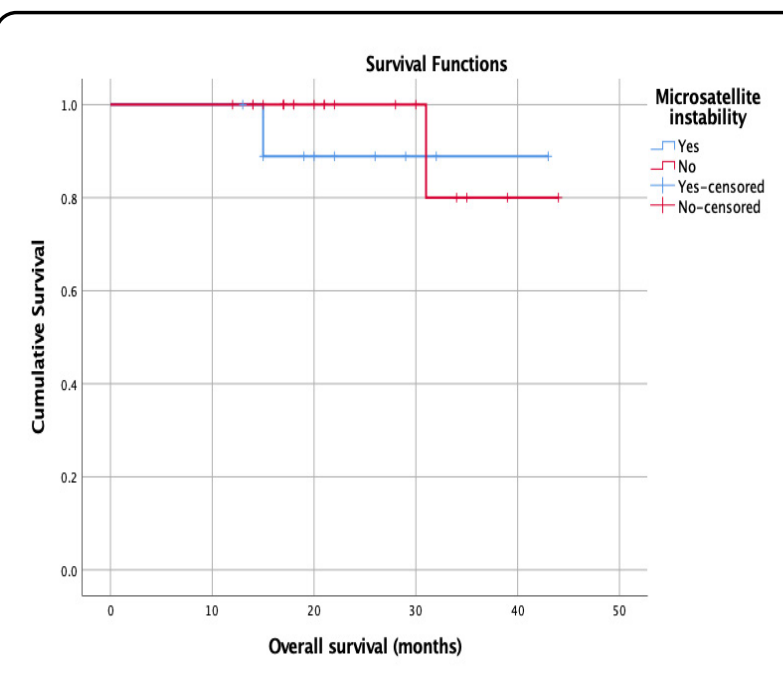

Figure 10: Patients who had microsatellite instability had higher overall survival than those who did not present it.

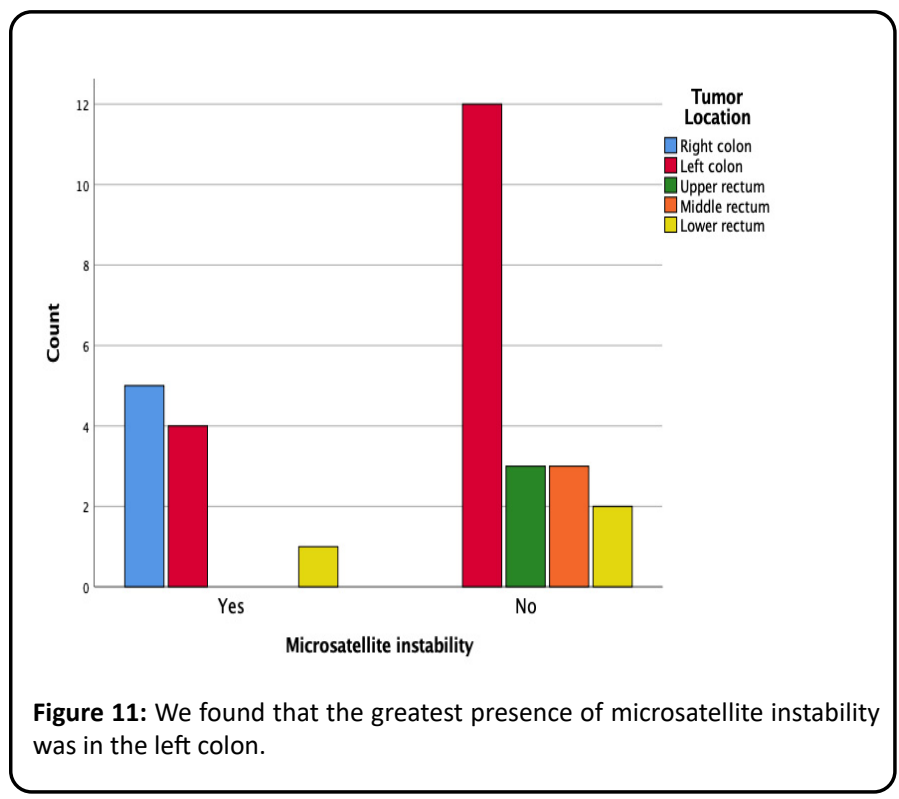

T2 (Stage II) was the most commonly found and where there was a higher recurrence rate, for that reason $50 \%$ of patients underwent surgery without adjuvant chemotherapy which has been demonstrated in the previous series and in the literature that the presence of risk factors including MSI is frequent in recurrent cases and sensitive to the use of Fluoroprymidine based chemotherapy, for that reason the group of non-adjuvant therapy was classified as of high risk for recurrence without taking into account other associated risk factors.

\section{Conclusion}

We can conclude that the population evaluated in our Hospital exhibited a different behavior than the one evaluated previously in the series reported worldwide in the literature. We observed a higher presence of microsatellite instability MSI and a higher prevalence of the tumor in the left colon as compared to the right colon with a higher risk as an independent factor for recurrence without taking into account the size of the tumor or the lymph node involvement that was reported in more than
$60 \%$ in our series, the elevation of ACE levels and the fact that half of the patients did not receive adjuvant chemotherapy with Fluoropyrimidine which further increases the risk of recurrence, and finally the presence of Microsatellite Instability had better overall survival. The testing for the presence of satellite instability in tumor tissue should be a new standard to evaluate the prevalence and risk of recurrence.

\section{Reference}

1. Ribic CM, Sargent DJ, Moore MJ, et al. (2003) Tumor Microsatellite-Instability Status as a Predictor of Benefit from Fluorouracil-Based Adjuvant Chemotherapy for Colon Cancer. $\mathrm{N}$ Engl J Med 349(3): pp. 247-257.

2. Boland CR, Goel A (2010) Microsatellite Instability in Colorectal Cancer. Gastroenterology 138(6): pp. 2073-2087.

3. Kloor M, Staffa L, Aysel Ahadova, et al. (2014) Clinical significance of microsatellite instability in colorectal cancer. Langenbecks Arch Surg 399(1): pp. 23-31.

4. Zeinalian $M$, Hashemzadeh-Chaleshtori $M$, Salehi $R$, et al. (2018) Clinical Aspects of Microsatellite Instability Testing in Colorectal Cancer. Adv Biomed Res 7: pp. 28.

5. He EY, Hawkins NJ, Mak G (2016) The Impact of Mismatch Repair Status in Colorectal Cancer on the Decision to Treat With Adjuvant Chemotherapy: An Australian Population-Based Multicenter Study. Oncologist 21(5): pp. 618-625.

6. Imai K, Hiroyuki Yamamoto H (2008) Carcinogenesis and microsatellite instability: the interrelationship between genetics and epigenetics. Carcinogenesis 29(4): pp. 673-680.

7. Morales C, Peinado MA (2006) Inestabilidad de microsatélites: papel diagnóstico e implicaciones pronósticas. GH Continuada. Enero-Febrero 5(1): pp. 18-22.

8. Senior K (2000) Microsatellite instability indicates better prognosis in colorectal cancer. The Lancet 355(4): 1245-1249.

9. Jiménez JJ, Blanes A, Diaz-Cano SJ (2003) Microsatellite Instability in Colon Cancer N England J Med 349: pp. 18-22.

10. Des Guetz G, Uzzan B, Nicolas P (2009) Microsatellite instability: a predictive marker in metastatic colorectal cancer? Targ Oncol 4(1): pp. 57-62.

11. Robert Gryfe Gallinger S (2001) Microsatellite instability, mismatch repair deficiency, and colorectal cancer. Surgery 130(1): pp. 17-20.

12. Sinicrope FA, Sargent DJ (2012) Cancer: prognostic, predictive and therapeutic implications Molecular Pathways: microsatellite instability in colorectal. Clin Cancer 18(6):15061512.

13. Sinicrope FA, Foster NR, Thibodeau SN, et al. (2011) DNA mismatch repair status and colon cancer recurrence and survival in clinical trials of 5-fluorouracil-based adjuvant therapy. J Natl Cancer Inst 103(11): pp. 863-875.

14. Jovera RYA (2003) Payáb Inestabilidad de microsatélites en el cáncer colorrectal: concepto, métodos de detección y utilidad clínica. Gastroenterol Hepatol 26(10): pp. 656-663.

15. Pino MS, Chung DC (2011) Microsatellite instability in the management of colorectal cancer Expert Rev. Gastroenterol. Hepatol 5(3): 385-399.

16. de la Chapelle A, Hampel $H$ Clinical Relevance of 
Microsatellite Instability in Colorectal Cancer. J Clin Oncol 28(20): pp. 3380-3387.

17. Müller I, Schulmann K, Reinacher-Schick A (2008) Predictive and prognostic value of microsatellite instability in patients with advanced colorectal cancer treated with a fluoropyrimidine and oxaliplatin containing first-line chemotherapy. A report of the AIO Colorectal Study Group C. Int J Colorectal Dis 23(11): pp. 1033-1039.

18. Fallik D, Borrini F, Boige V, et al. (2003) Microsatellite Instability Is a Predictive Factor of the Tumor Response to Irinotecan in Patients with Advanced Colorectal Cancer. Cancer Research 63(18): pp. 5738-5744.

19. Bertagnolli MM, Niedzwiecki D, Compton CC, et al. (2009) Microsatellite Instability Predicts Improved Response to Adjuvant Therapy With Irinotecan, Fluorouracil, and Leucovorin in Stage III Colon Cancer: Cancer and Leukemia Group B Protocol 89803. J Clin Oncol 27(11): 1814-1821.

20. Saridaki Z, Souglakos J, Georgoulias V (2014) Prognostic and predictive significance of MSI in stages II/III Colon Cancer. World J Gastroenterol 20(22): pp. 6809-6814.

21. Schmitz L, Moretti L, Marino L, et al. (2014) Estudio Fenotípico de inestabilidad microsatelital en cáncer colorrectal. Correlación con parámetros histológicos y clínicos. Rev Esp Patol 47(4): pp. 204-209.

22. Kawakami H, Zaanan A (2015) Microsatellite Instability Testing and Its Role in the Management of Colorectal Cancer. Curr Treat Options Oncol 16(7): pp. 30.

23. Zhang L, Zhao J, Yu B (2017) Correlations between microsatellite instability, ERCC1/XRCC1 polymorphism and clinical characteristics, and FOLFOX adjuvant chemotherapy effect of colorectal cancer patients. Cancer Genetics 218-219: 51-57.

24. Buecher B, Cacheux W, Rouleau E (2013) Role of Microsatelite instability in the management of colorectal cancers. Dig Liver Dis 45(20): pp. 441-449. 